\title{
Synthesis and Characterization of Micro-nano Carbon Filler from Jatropha Seeds
}

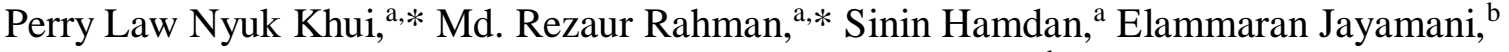 \\ Muhammad Khusairy Bin Bakri, ${ }^{a}$ and Khairuddin Sanaullah ${ }^{\mathrm{c}, \mathrm{d}}$
}

\begin{abstract}
Biochar was synthesized from biomass (jatropha seeds) through a low microwave pyrolysis temperature of $180^{\circ} \mathrm{C}$ with microwave power of $2 \mathrm{~kW}$. A ball milling process reduced the jatropha seed biochar size and converted it into micro-nano carbon biofiller. After ball milling, the biochar size was reduced from 1 to $3 \mathrm{~mm}$ to the $10 \mu \mathrm{m}$ to $600 \mathrm{~nm}$ range, which is around a $90 \%$ reduction in size. Fourier-transform infrared spectroscopy (FTIR), scanning electron microscopy (SEM), energy dispersive X-ray spectroscopy (EDS), and Brunauer-Emmett-Teller (BET) analysis were used to determine the jatropha seed biofillers properties with respect to the ball milling processes. BET results revealed increasing surface area from 0.10 to $3.67 \mathrm{~m}^{2} / \mathrm{g}$, and EDS results revealed the elemental composition of the jatropha seed biofillers. The carbon mass percentage increased from 72.6 to $81.2 \%$. Both results were after ball milling for 30 hours. The FTIR results revealed an increase in transmittance intensity and some reduction in peaks after ball milling. Production of micro-nano carbon fillers from microwave pyrolysis jatropha seeds biochar are applicable as reinforcement fillers for high strength composite material fabrications. Scanning electron microscopy, EDS, FTIR, and BET analysis results indicated size reduction of the biochar with increased carbon content from 72.6 to $81.2 \%$ as surface area increased from 0.10 to 3.67 $\mathrm{m}^{2} / \mathrm{g}$ after 30 hours of ball milling.
\end{abstract}

Keywords: Format; Synthesis; Characterization; Micro; Nano; Carbon; Jatropha

Contact information: a: Faculty of Engineering, Universiti Malaysia Sarawak, Jalan Datuk Mohammad Musa, Kota Samarahan, Sarawak, Malaysia; b: Faculty of Engineering, Computing and Science, Swinburne University of Technology Sarawak Campus, 93350 Kuching, Sarawak, Malaysia; c: Informetrics Research Group, Ton Duc Thang University, Ho Chi Minh City, Vietnam; d: Faculty of Applied Sciences, Ton Duc Thang University, Ho Chi Minh City, Vietnam;

*Corresponding authors: perrylaw93@hotmail.com; rmrezaur@unimas.my

\section{INTRODUCTION}

Jatropha seeds have gained interest with researchers due to their potential as a source of bio-oil. Jatropha curcas L. belongs to the family Euphorbiaceae and is a deciduous shrub that can grow to a height of $3 \mathrm{~m}$ to $5 \mathrm{~m}$, with a productive lifespan of 50 years (Ugbogu et al. 2014). Srivastava et al. (2013) reported numerous case studies showing that jatropha seeds have high oil content, with potential application as an alternative to diesel. Depending on the variety, the seeds may contain 40 to $60 \%$ of oil. In recent years, several studies have been conducted examining jatropha seeds for production of bio-oil, measuring their properties and characteristics (Ugbogu et al. 2014; Kadry 2015; Audu et al. 2018). After extraction of the bio-oil, an alternative method of disposal alongside other organic waste utilizes microwave-assisted pyrolysis to yield biochar, which may be beneficial for numerous applications. There are several studies supporting pyrolysis 
of jatropha fruit, which includes the seeds and cakes, to obtain both biochar and syngas (Figueiredo et al. 2011; Kanaujia et al. 2016; Odetoye et al. 2019).

Biochar has many applications, including soil modification in the agricultural sector and adsorption of heavy metals or dyes in industrial sectors. Li et al. (2019) reported microwave-pyrolysis biochar of Artemisia selengensis and its adsorption capacity for methylene blue, for which biochar pores, surface area, and pyrolysis conditions influenced the adsorption capabilities (Li et al. 2019). In a similar study on adsorption capabilities, Bakly et al. (2019) reported nitrate removal with macadamia nutshell biochar from slow pyrolysis; more than $45 \%$ of nitrate was removed at the highest concentration and at the lowest flow rate. Bakly et al. (2019) also attributed the adsorption capabilities to the biochar size, porosity, and surface area; the biochar samples were ground and sieved with a size range of $1.18 \mathrm{~mm}$ to $2.30 \mathrm{~mm}$ before adsorption testing. Furthermore, agricultural runoff is a major cause of degradation to freshwater sources, so the removal of nitrate content is a concern, due to the abundance of nitrogen-based fertilizers in agriculture (Bakly et al. 2019).

In studies of microwave-assisted pyrolysis, some researchers altered the microwave power in their experiment, in comparison to the alteration of temperature. The differences in microwave power led to monitoring the maximum temperature of the biomass, and researchers associated the maximum temperature achieved with biochar and oil yields. Huang et al. (2016) stated that the product yields among some studies are relatively different, as some studies have differed in product yield by varying factors such as, biomass characteristics, particle size, sample weight, microwave power, reaction temperature, reaction time, product vapor residence time, reactor design, and microwave heating manner. Among the studies, the reaction temperature appeared to be the main attribute influencing the product yield. A study by Budarin et al. (2009) reported the microwaveassisted pyrolysis of wheat straw at a maximum-minimum temperature of $180{ }^{\circ} \mathrm{C}$, achieving product yields with mass percentages of $29 \%, 20.6 \%, 36.4 \%$, and $14 \%$ for biochar, organics, water, and gas, respectively. With the addition of $\mathrm{HCl}, \mathrm{H}_{2} \mathrm{SO}_{4}$, and $\mathrm{NH}_{3}$, the researchers achieved greater biochar and gas yields in comparison to the neat wheat straw microwave-assisted pyrolysis sample at the same temperature (Budarin et al. 2009).

Some other studies have reported similar percentage product yields under lowtemperature microwave-assisted pyrolysis, ranging from $180^{\circ} \mathrm{C}$ to $600{ }^{\circ} \mathrm{C}$, varying among the studies (Zhou et al. 2013; Zhang et al. 2015a, 2015b). According to Zhang et al. (2019), the pyrolysis preparation method may influence biochar characteristics such as biochar yield, pore size, surface area, and hydrophobicity; and ball milling is a good, low-cost modification method to increase biochar sorption capabilities and influence the hydrophobicity, by modification into micro-nano biochar powders.

According to a review of the literature, there has been a lack of studies focusing on producing micro-nano carbon fillers from any pyrolysis product. Most researchers only concentrate on the study of oil or biochar from the pyrolysis of biomass, as well as the types of pyrolysis process. Hence affirming the research gap, the aim for this research is to produce micro-nano carbon filler from microwave pyrolysis jatropha seeds biochar, utilizing a ball milling process. The production of micro-nano carbon filler may be implemented as reinforcement filler in applications for high strength composite material fabrications.

In this study, it could be highlighted that jatropha seed undergoes microwave pyrolysis at low pyrolysis temperature of $180{ }^{\circ} \mathrm{C}$ with a microwave power of $2 \mathrm{~kW}$. The resulting biochar was ball-milled to decrease size and increase surface area, achieving a 
micro-nano size range carbon biofiller. Variations of ball milling durations was investigated to understand when a micro-nano range has been achieved. Scanning electron microscopy (SEM), Energy dispersive X-ray spectroscopy (EDS), Fourier-transform infrared spectroscopy (FTIR), and Brunauer-Emmett-Teller (BET) analysis were used to investigate the characteristics of the ball-milled jatropha seed carbon biofiller, which includes changes in size, surface area, and composition.

\section{EXPERIMENTAL}

\section{Materials}

The jatropha seeds were supplied by Universiti Malaysia Sarawak (UNIMAS) (Kota Samarahan, Sarawak, Malaysia) and were air-dried prior to storage for subsequent use. A Kholler CT114A Pyrolyser 5010 (Kuala Lumpur, Malaysia) was used for the microwave pyrolysis process. A Retsch PM400 Planetary Ball Mill (Retsch GmbH, Haan, Germany) was used for all the ball milling processes. A Panasonic MX-AC400 Mixer Grinder (Panasonic Corporation, Kadoma, Japan) was used before the ball milling process as prerequisite to assist the ball milling process. A Fourier-transform infrared spectrophotometer (IRAffinity-1, Shimadzu Corporation, Kyoto, Japan) was used for the FTIR analysis of the dried jatropha seeds, biochar, and biofillers for comparison. A Hitachi TM4000Plus tabletop microscope with a Quantax75 TM series energy dispersive X-ray spectrometer (Hitachi, Ltd., Tokyo, Japan) was used for the SEM and EDS analyses of the jatropha seed biochar and biofillers to investigate the composition, surface structure, and size. A Quantachrome Autosorb iQ (Quantachrome Instruments, Boynton Beach, FL, USA) was used for the BET surface area analysis of the Jatropha seed biochar and biofillers. All experiments were conducted in the analytical chemistry lab of the Department of Chemical Engineering, UNIMAS.

\section{Methods}

\section{Microwave pyrolysis of jatropha seeds}

First, $100 \mathrm{~g}$ of slightly ground jatropha seeds was placed into a borosilicate beaker and into the microwave reactor chamber. The seeds were ground slightly to accommodate the beaker size. Prior to the microwave pyrolysis process, the microwave reactor chamber was purged using a vacuum pump to create an oxygen-free environment. The pyrolysis process was performed for $10 \mathrm{~min}$ for 3 rounds to 4 rounds under the following operating conditions: a microwave power of $2 \mathrm{~kW}$, pyrolysis temperature set at $180{ }^{\circ} \mathrm{C}$, a nitrogen flow rate of $0.5 \mathrm{~L} / \mathrm{min}$, and a chamber vacuum pressure of $0.8 \mathrm{kPa}$. After each round, the Jatropha seeds were stirred manually for even heat distribution, as the microwave reactor did not have a motorized turntable. This eliminated the variable hotspots during the microwave pyrolysis process. After completing microwave pyrolysis, the biochar and the condensed residual oil were collected.

\section{Ball milling of biochar into biofiller}

Before ball milling, the biochar was ground for a total of $5 \mathrm{~min}$ at the highest speed (approximately 18,000 to 20,000 RPM) with the mixer grinder. This was performed to ensure an even biochar powder to assist the ball milling process, according to the planetary ball mill specifications. Two cylindrical $25-\mathrm{mL}$ vessels, each with 20 stainless steel balls weighing $0.5 \mathrm{~g}$, was used during the ball milling process, in which biochar was added up 
to $60 \%$ of the volume of each vessel. Two vessels were utilized to efficiently process more biochar into micro-nano biofiller. The biochar was ball milled for a total of $30 \mathrm{~h}$, while samples were taken for testing at $4 \mathrm{~h}, 8 \mathrm{~h}, 12 \mathrm{~h}, 16 \mathrm{~h}, 20 \mathrm{~h}, 25 \mathrm{~h}$, and $30 \mathrm{~h}$.

\section{Characterization and Testing}

SEM and EDS analyses of biochar and biofiller

Scanning electron microscopy for the samples was conducted according ASTM E2015-04 (2014), in regard to electron microscopy testing procedure. Magnifications of $1000 \times$ were utilized to observe numerous jatropha seed biochar and biofiller samples. In addition, EDS was conducted according to ASTM E1508-12a (2019); three points were selected at random areas of the samples. The software automated the analysis of the elemental composition percentages. The EDS was repeated numerous times for each sample, and the most representative results were selected.

\section{FTIR of biochar and biofiller}

Fourier-transform infrared spectroscopy was conducted according to the ASTM E168-16 (2016) and ASTM E1252-98 (2013) standards for qualitative and quantitative analysis. The spectrum scanning was conducted in the wavenumber range of 4000 to 400 $\mathrm{cm}^{-1}$ for each sample. Fourier-transform infrared spectroscopy utilized the infrared spectrum transmittance and absorption of the samples to develop a unique molecular fingerprint spectrum. The test was repeated numerous times for each sample, and the most representative results were selected.

\section{BET surface area of biochar and biofiller}

The BET surface area analysis was conducted according to the ASTM D6556-14 (2014) standard. The degassing temperature was set at $130{ }^{\circ} \mathrm{C}$ for $3 \mathrm{~h}$. Lab technicians at UNIMAS assisted in conducting the experiment. The test was repeated numerous times for each sample, and the most representative results were selected.

\section{RESULTS AND DISCUSSION}

\section{FTIR}

The FTIR results for the dried jatropha seeds, jatropha seed biochar before ball milling (BBM), and jatropha seed biochar after $30 \mathrm{~h}$ of ball milling (ABM30hours) are shown in Fig. 1.

As shown in Fig. 1, BBM and ABM30hours showed increased transmittance intensities in comparison to dried jatropha seeds. This result could be due to the development of pores and internal structure of the biochar after microwave pyrolysis and ball milling (Cheng and Li 2018). In the region from 3800 to $3100 \mathrm{~cm}^{-1}$, the peak bands could be characterized as $\mathrm{O}-\mathrm{H}$ stretching and $\mathrm{H}$-bonds consisting of alcohols, phenols, and water. The peaks detected for dried jatropha seeds and BBM were broader and deeper in this region compared to ABM30hours, indicating a reduction of alcohols, phenols, and water (Jouiad et al. 2014). Ball milling process generates heat due to high impact energy and friction, hence allowing the release of moisture. In which explains the reduction of alcohols, phenols, and water for ABM30hours.

Double peak bands in the region from $3000 \mathrm{~cm}^{-1}$ to $2800 \mathrm{~cm}^{-1}$ could be characterized as $\mathrm{C}-\mathrm{H}$ stretching, consisting of alkanes. Peaks detected for ABM30hours 
were slightly broader and shorten in this region compared to BBM, which could be associated with the size reduction and increased surface area after ball milling processes, affecting the presence of the biochar surface functional groups (Zhang et al. 2019).
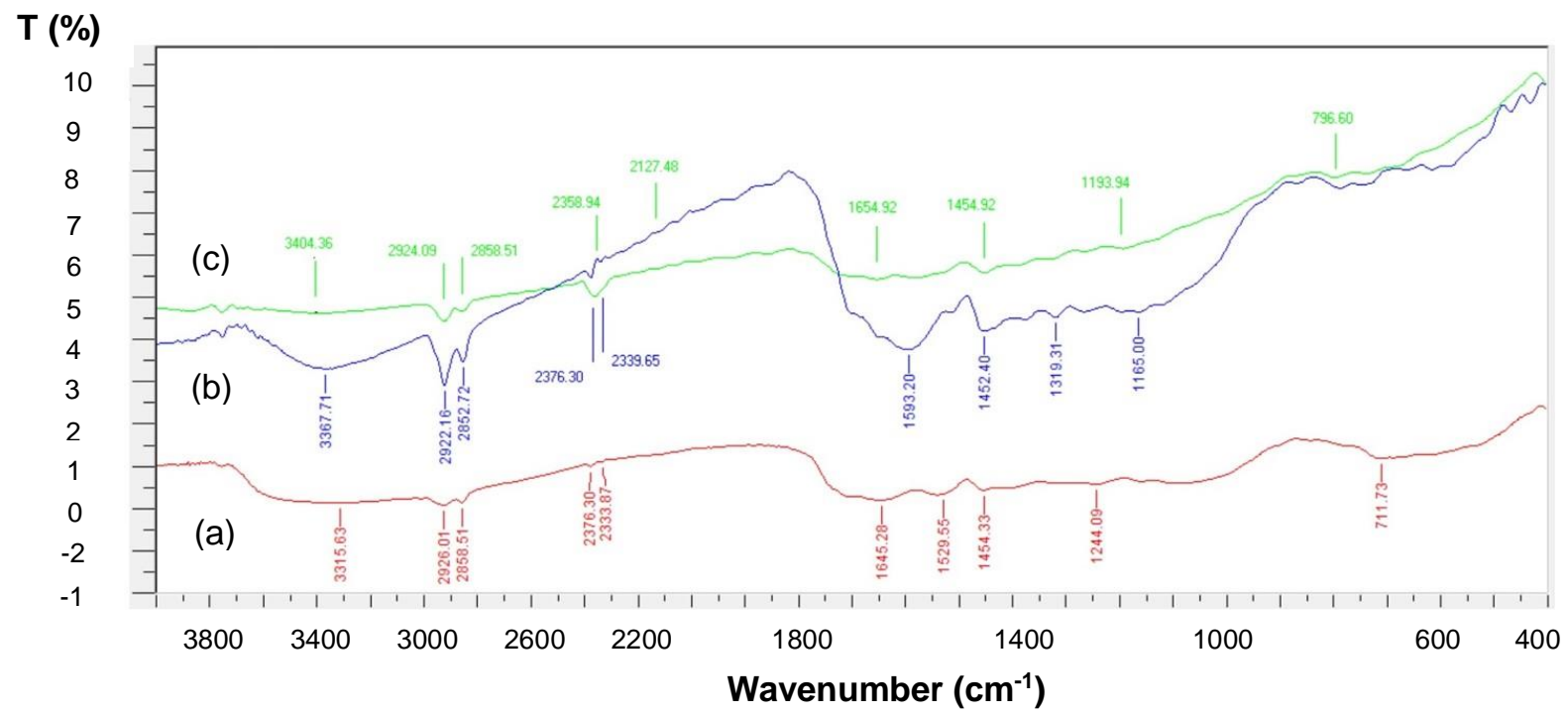

Fig. 1. FTIR results for (a) dried jatropha seeds, (b) BBM, and (c) ABM30hours

In the region from $2400 \mathrm{~cm}^{-1}$ to $2200 \mathrm{~cm}^{-1}$, peaks for both BBM and ABM30hours could be characterized as $\mathrm{O}=\mathrm{C}=\mathrm{O}$ stretching (carbon dioxide, $\mathrm{CO}_{2}$ ). As shown in the spectrum, there was a slight shift in the peaks and transmittance intensity for ABM30hours compared to $\mathrm{BMM}$, indicating a lower presence of $\mathrm{CO}_{2}$. The ball milling process decrease size $\&$ increase surface area of the biochar may cause the slight shift in peaks indicating a lower presence in $\mathrm{CO}_{2}$. Similar effects could be seen in one study which chemically pretreats biochar and diminishing peaks of $\mathrm{CO}_{2}$ caused by pyrolysis process (Meri et al. 2018). Hence, ball milling may have similar effects as some chemical pretreatments on biochars.

In the region from $1600 \mathrm{~cm}^{-1}$ to $1500 \mathrm{~cm}^{-1}$, peak bands detected for ABM30hours and $\mathrm{BBM}$ could be characterized as alkenes' $-\mathrm{C}=\mathrm{C}-$ stretches. As shown in the spectrum, ABM30hours had stronger peaks compared to BBM, with a slight decrease in transmittance intensity. This result indicates some degree of biochar activation due to increased surface area, as was the case for the region from $3000 \mathrm{~cm}^{-1}$ to $2800 \mathrm{~cm}^{-1}$ (Tongpoothorn et al. 2011).

\section{EDS of Biochar}

Table 1 shows the EDS element contents for BBM. Figure 2 shows the spectrum graph in correlation with the data in Table 1. Elements present in the sample, according to Table 1, were carbon $(\mathrm{C})$, oxygen $(\mathrm{O})$, potassium $(\mathrm{K})$, magnesium $(\mathrm{Mg})$, phosphorus $(\mathrm{P})$, calcium $(\mathrm{Ca})$, aluminum $(\mathrm{Al})$, and platinum $(\mathrm{Pt})$.

Table 2 shows the EDS element content for ABM30hours. Figure 3 shows the spectrum graph in correlation with the data in Table 2. Elements present in the sample, according to Table 2, were carbon $(\mathrm{C})$, oxygen $(\mathrm{O})$, potassium $(\mathrm{K})$, magnesium $(\mathrm{Mg})$, phosphorus (P), calcium (Ca), and iodine (I), which could be negligible, as the mass percentage detected was zero. 
Table 1. EDS Element Composition for BBM

\begin{tabular}{|c|c|c|c|c|c|}
\hline Element & Atomic No. & Mass (\%) & Atom (\%) & $\begin{array}{c}\text { Absolute } \\
\text { Error (\%) (1 } \\
\text { sigma) }\end{array}$ & $\begin{array}{c}\text { Relative } \\
\text { Error (\%) (1 } \\
\text { sigma) }\end{array}$ \\
\hline $\mathrm{C}$ & 6 & 72.57 & 80.39 & 7.97 & 10.98 \\
\hline $\mathrm{O}$ & 8 & 19.93 & 16.58 & 2.54 & 12.72 \\
\hline $\mathrm{K}$ & 19 & 2.36 & 0.80 & 0.10 & 4.23 \\
\hline $\mathrm{Mg}$ & 12 & 1.49 & 0.82 & 0.11 & 7.10 \\
\hline $\mathrm{P}$ & 15 & 1.44 & 0.62 & 0.08 & 5.66 \\
\hline $\mathrm{Ca}$ & 20 & 1.32 & 0.44 & 0.07 & 5.13 \\
\hline $\mathrm{Al}$ & 13 & 0.70 & 0.35 & 0.06 & 8.47 \\
\hline $\mathrm{Pt}$ & 78 & 0.18 & 0.01 & 0.03 & 19.21 \\
\hline
\end{tabular}

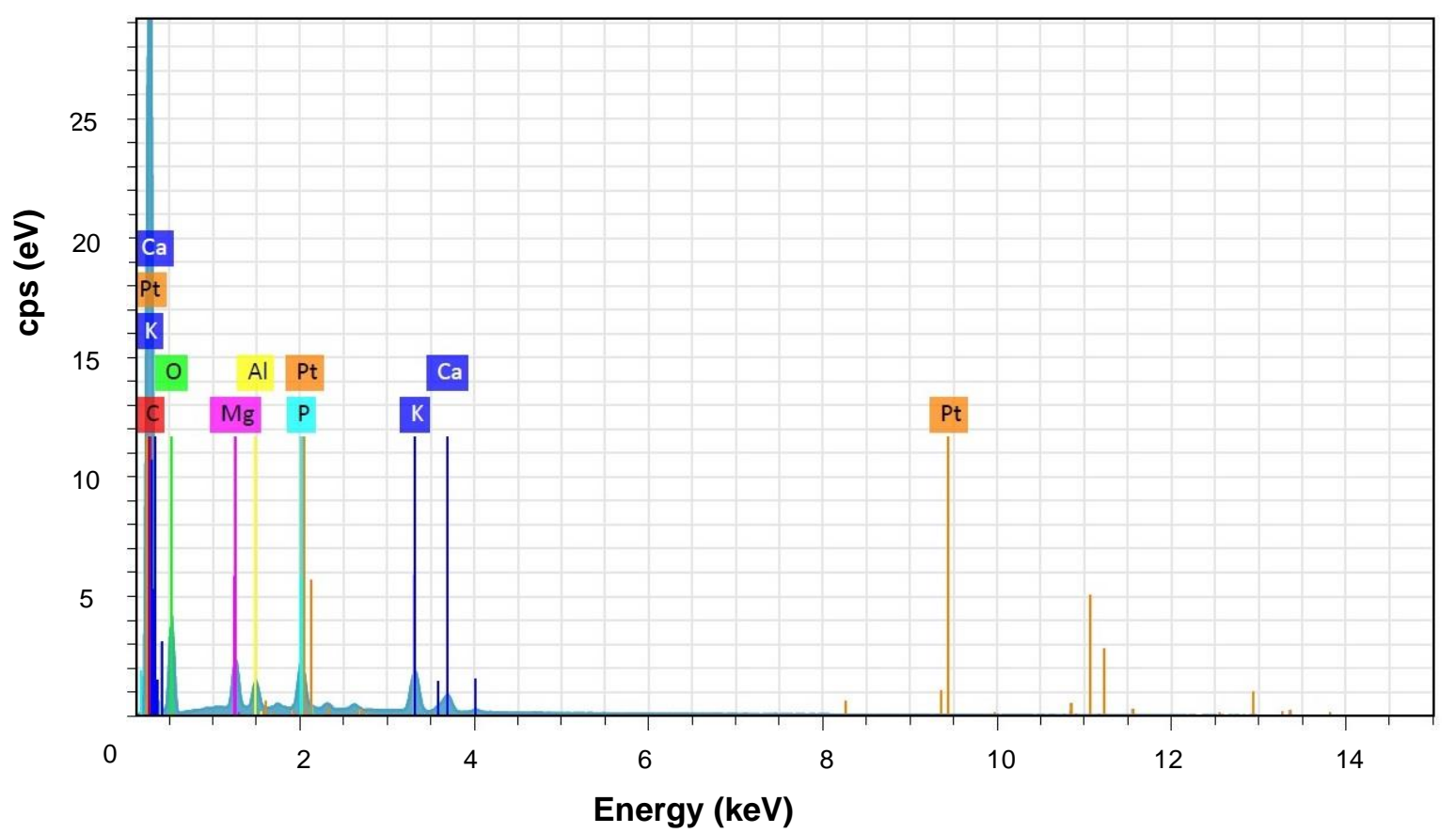

Fig. 2. EDS spectrum graph for Jatropha seed biochar before ball milling

Table 2. EDS Element Composition for ABM30hours

\begin{tabular}{|c|c|c|c|c|c|}
\hline Element & Atomic No. & Mass (\%) & Atom (\%) & $\begin{array}{c}\text { Absolute } \\
\text { Error (\%) (1 } \\
\text { sigma) }\end{array}$ & $\begin{array}{c}\text { Relative } \\
\text { Error (\%) (1 } \\
\text { sigma) }\end{array}$ \\
\hline $\mathrm{C}$ & 6 & 81.17 & 86.19 & 9.29 & 11.45 \\
\hline $\mathrm{O}$ & 8 & 15.97 & 12.73 & 2.47 & 15.49 \\
\hline $\mathrm{K}$ & 19 & 1.33 & 0.43 & 0.07 & 5.52 \\
\hline $\mathrm{Mg}$ & 12 & 0.53 & 0.28 & 0.06 & 11.11 \\
\hline $\mathrm{Ca}$ & 20 & 0.53 & 0.17 & 0.05 & 9.25 \\
\hline $\mathrm{P}$ & 15 & 0.47 & 0.19 & 0.05 & 10.25 \\
\hline $\mathrm{I}$ & 53 & 0 & 0 & 0 & 0.90 \\
\hline
\end{tabular}




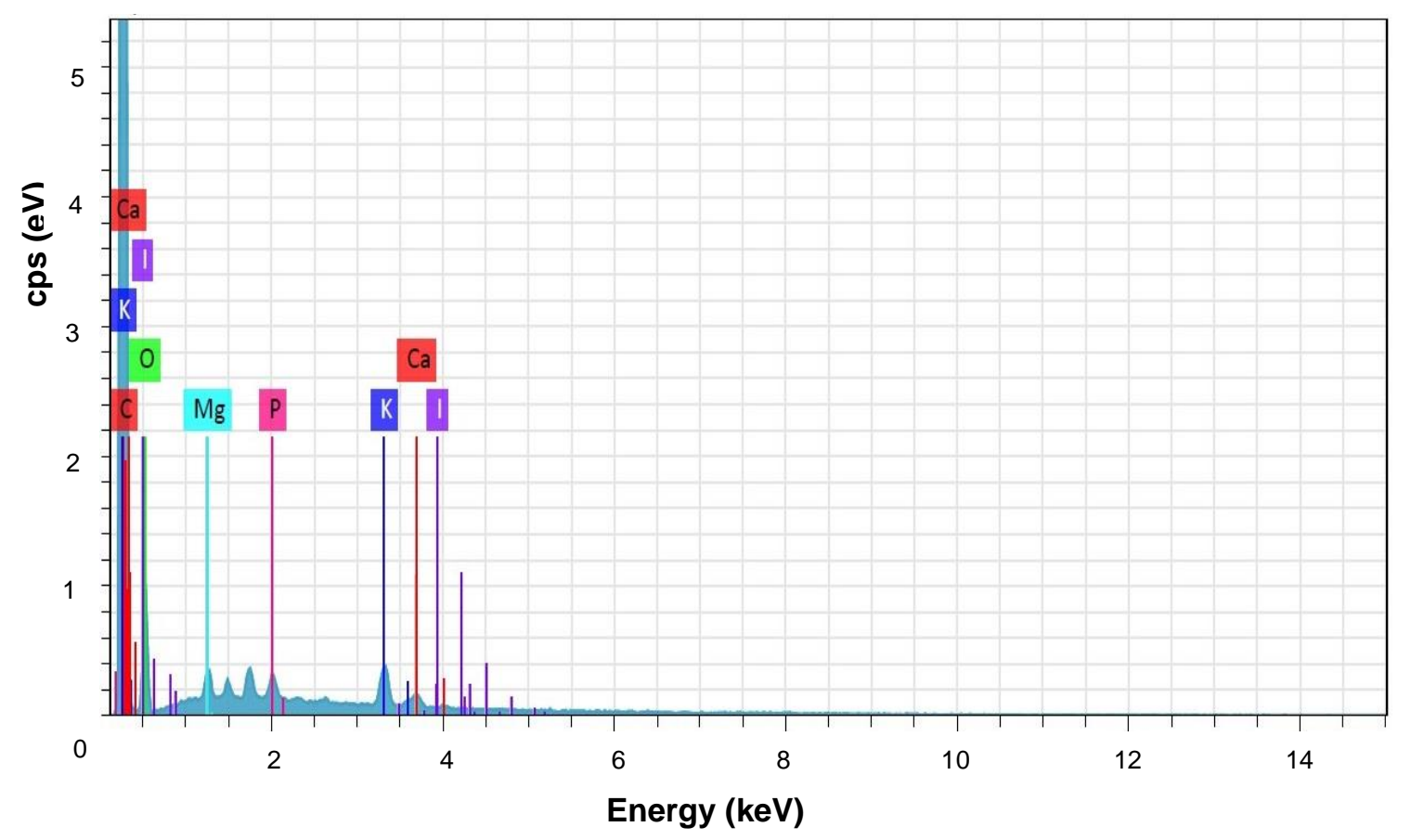

Fig. 3. EDS spectrum graph for ABM30hours

In total, there were eight elements potentially detected in the jatropha seed biochar samples according to the EDS results. The eight elements detected were carbon $(\mathrm{C})$, oxygen $(\mathrm{O})$, potassium $(\mathrm{K})$, magnesium $(\mathrm{Mg})$, phosphorus $(\mathrm{P})$, calcium $(\mathrm{Ca})$, aluminium $(\mathrm{Al})$, and platinum $(\mathrm{Pt})$.

Comparing Tables 1 and 2, the carbon mass percentage of the jatropha seed biochar increased, while the other remaining elements decreased in mass percentage. The changes in the mass percentages of the elemental components could be due to the effects of ball milling conditions, i.e., milling time and ball-sample ratio. One study illustrated similar results, where the changes in mass percentage occurred with altering milling conditions (Supriyono et al. 2018). It was noted that carbon was also the most dominant element presence in their study, and the reduced particle size did increase carbon mass percentage indicated by their EDS experimental result. The results of work by Supriyono et al. (2018) showed the smallest biochar particle size to be $274 \mathrm{~nm}$, with a carbon mass percentage of $93.0 \%$.

Carbon, oxygen, potassium, magnesium, calcium, and phosphorous were the common elements present in the samples, with carbon having the greatest mass percentage. Moreover, the results listed in Tables 1 and 2 show that the carbon mass percentage increased from 72.6 to $81.2 \%$ for ABM30hours. One of the major correlates of carbon content in biochar is the method of production of the biochar, i.e. pyrolysis, carbonization, and processing time and temperature (Kim et al. 2012; Kloss et al. 2012; Al-Wabel et al. 2013). The varied elemental compositions could also be associated with the consistency of the EDS machine to detect and characterize elements present in the sample. Carbon content could possibly have been presentable during the EDS experiment due to the distribution of particles caused by size reduction and increased surface area, due to the ball milling processes (Zhang et al. 2019). 


\section{SEM of Biochar}

Overall, the results obtained from SEM showed that the jatropha seed biochar progressively decreased in size after an extended duration of ball milling, totalling up to $30 \mathrm{~h}$ of ball milling.
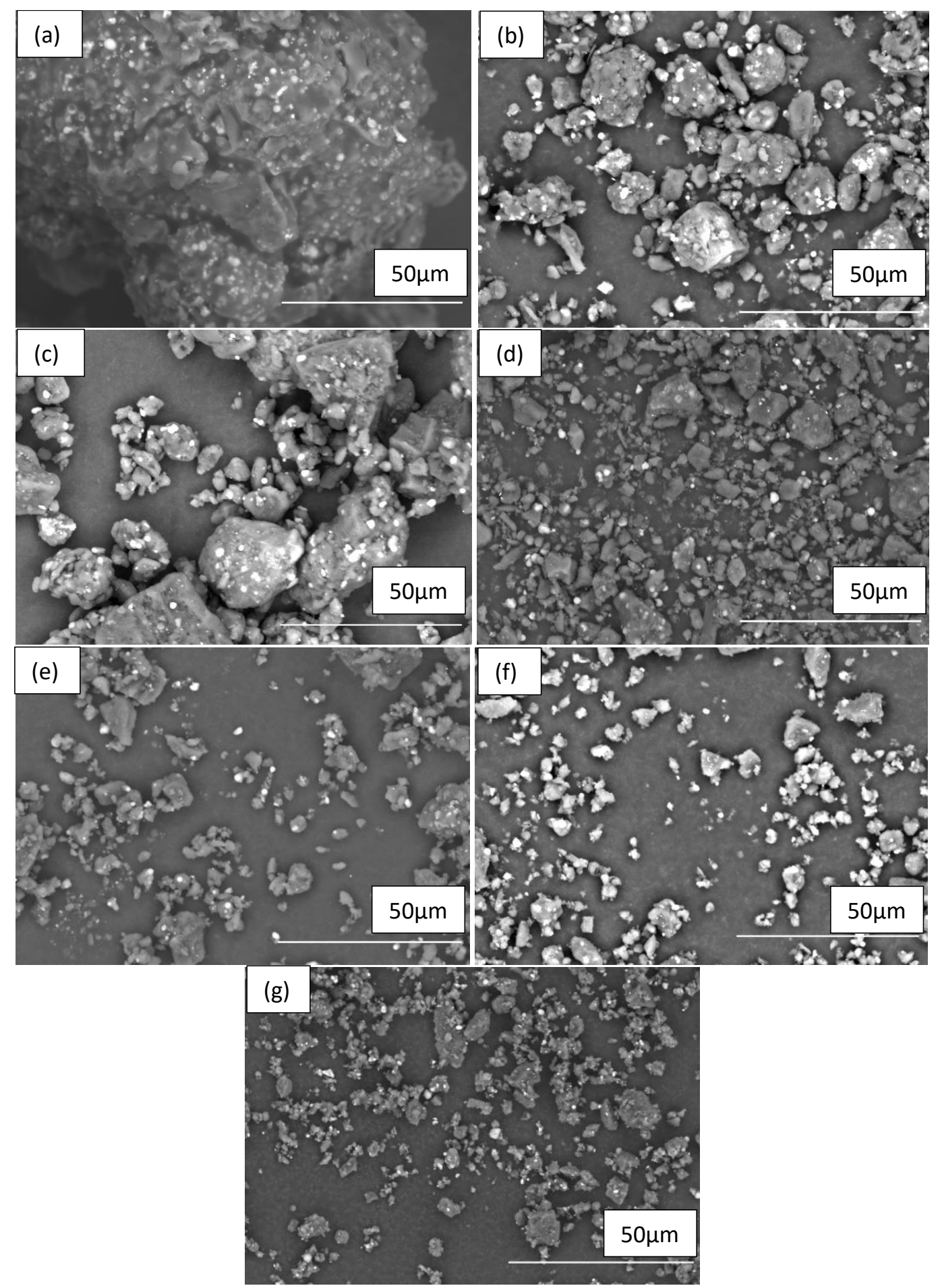

Fig. 4. SEM images at $1000 \times$ magnification for jatropha seed biochar: (a) BBM, (b) ABM4hours, (c) ABM8hours, (d) ABM12hours, (e) ABM16hours, (f) ABM25hours, and (g) ABM30hours 
The jatropha seed biochar sample in Fig. 4(a) shows millimeter-size chunks (1-3 $\mathrm{mm})$ with a rough surface structure, in which numerous macropores were present. The samples shown in Fig. 4(b) and 4(c) may look similar in size, but both exhibited notable size reductions after ball milling, compared to the sample in Fig. 4(a). As the duration of ball milling approached and exceeded $12 \mathrm{~h}$, Fig. 4(d), 4(e), and 4(f) show that the jatropha seed biochar samples were further reduced in size and developed characteristic agglomerates comprising finer jatropha seed biochar particles attached onto the larger pieces (Tsai et al. 2019).

A great reduction in size overall is shown in Fig. 4(g) for ABM30hours, where agglomeration characteristics and a finer chip-like branches consistency of the biochar were more present (Wang et al. 2019; Zhang et al. 2019).

For ABM30hours, the jatropha seed biochar particles were observed to be in the micro-size range between $1 \mu \mathrm{m}$ to $10 \mu \mathrm{m}$, and 400 to $600 \mathrm{~nm}$ noticeably branching together with the micro size particles. The agglomeration characteristics of the jatropha seed biochar may be attributed to the biochar not reaching the grinding limit. Overall, after ball milling, jatropha seed biochar size were reduced from 1 to $3 \mathrm{~mm}$ to the $10 \mu \mathrm{m}$ to $600 \mathrm{~nm}$ range, which represents a reduction in size of around $90 \%$. By altering ball milling conditions, i.e., increasing milling time and ball-sample ratio, agglomeration could be prevented, and the grinding limit can be reached. A grinding limit is the point where the duration/cycles of ball milling will no longer affect the particle size of the sample, and the sample is homogenous (Eckert and Börner 1997; Umemoto et al. 2001). Impact energy during ball milling may be affected, in correlation to altering ball the milling conditions (Supriyono et al. 2018).

\section{BET Analysis of Biochar}

Overall, the BET results indicated an increase in surface area after ball milling (Table 3). The smallest surface area was observed for BBM, at $0.10 \mathrm{~m}^{2} / \mathrm{g}$. The greatest surface area was observed for ABM30hours, at $3.67 \mathrm{~m}^{2} / \mathrm{g}$. This was a great increase in surface area, supporting the SEM results, which illustrated that the jatropha seed biochar particles had reduced to micro-nano size. The overall surface area was considerably smaller in comparison to other studies of jatropha seed biochar (Tongpoothorn et al. 2011; Garg and Das 2018; Zhang et al. 2019). Nevertheless, ball milling did increase the surface area by reducing the biochar from millimeter-size pieces into fine powders within the micronano size range. By contrast, the other studies were conducted within a macro size range. The type of pyrolysis process and the specific conditions (such as temperature, nitrogen gas flow rate, and time) may influence the initial surface area of the biochar before ball milling (Zhou et al. 2013; Zhang et al. 2015b; Zuo et al. 2018; Zhang et al. 2019). One study states that the pyrolysis temperature, among other conditions, has a large correlation to surface area and pore size due to the release of more volatiles from the biomass (Cheng and Li 2018). This explains the small surface area of the jatropha seed biochar samples, which may still contain some oils or volatiles from the microwave pyrolysis process. The increased surface areas of the biochar samples are established by the multi-point and isotherm BET plots presented in Figs. 5 to 7. According to Fig. 5, as the ball milling time increased, the volume at STP (cc/g) also increased, demonstrating the increased surface area of the jatropha seed biochar. Similarly, Figs. 6 and 7 show the increasing adsorption and desorption of the biochar samples with increasing duration of ball milling. The data presented also relates with the volume at STP (cc/g), further supporting the increased surface area after ball milling. A literature indicates there is a relation between the BET 
isotherm plot with adsorption characteristic of $\mathrm{Pb}$ (II) using biochar. Isotherm plots could be used to detected adsorption capabilities of the biochar, and the literature best describe such adsorption behavior of $\mathrm{Pb}$ (II) using biochar to be a monolayer adsorption (Wu, Q et.al 2019). In relation to this study, BET isotherm plots showed increased adsorption capabilities of the biochar with increased ball milling duration (i.e. particle size reduction and increased surface area).

The biochar preparation methods could influence the biochar yield, carbon content, pore size, and initial surface area prior to the ball milling process. Future investigation on optimizing preparation variables could yield biochar with greater carbon content, porosity, and surface area. The preparation variables include; methods to produce the biochar (i.e. pyrolysis, carbonization), production conditions (i.e. temperature, time, pressure, and gas flow rate), and ball-ratio for ball milling processes.

Referring to Figs. 5, 6, and 7, $P_{0}$ is the gas saturation pressure, $P / P_{0}$ is the pressure of the adsorbate relative to its saturation pressure, known as the relative pressure, and $P$ is the partial saturation pressure of the adsorptive gas in equilibrium with the surface.

Table 3. BET Results for All Jatropha Seed Biochar Samples (Surface Area)

\begin{tabular}{|c|c|}
\hline Jatropha Seed Biochar Sample & Surface Area $\left(\mathrm{m}^{2} / \mathrm{g}\right)$ \\
\hline Before ball milling $(0 \mathrm{~h})$ & 0.10 \\
\hline Ball milling $(4 \mathrm{~h})$ & 1.14 \\
\hline Ball milling $(8 \mathrm{~h})$ & 2.16 \\
\hline Ball milling $(12 \mathrm{~h})$ & 2.51 \\
\hline Ball milling $(16 \mathrm{~h})$ & 3.21 \\
\hline Ball milling $(25 \mathrm{~h})$ & 3.51 \\
\hline Ball milling $(30 \mathrm{~h})$ & 3.67 \\
\hline
\end{tabular}

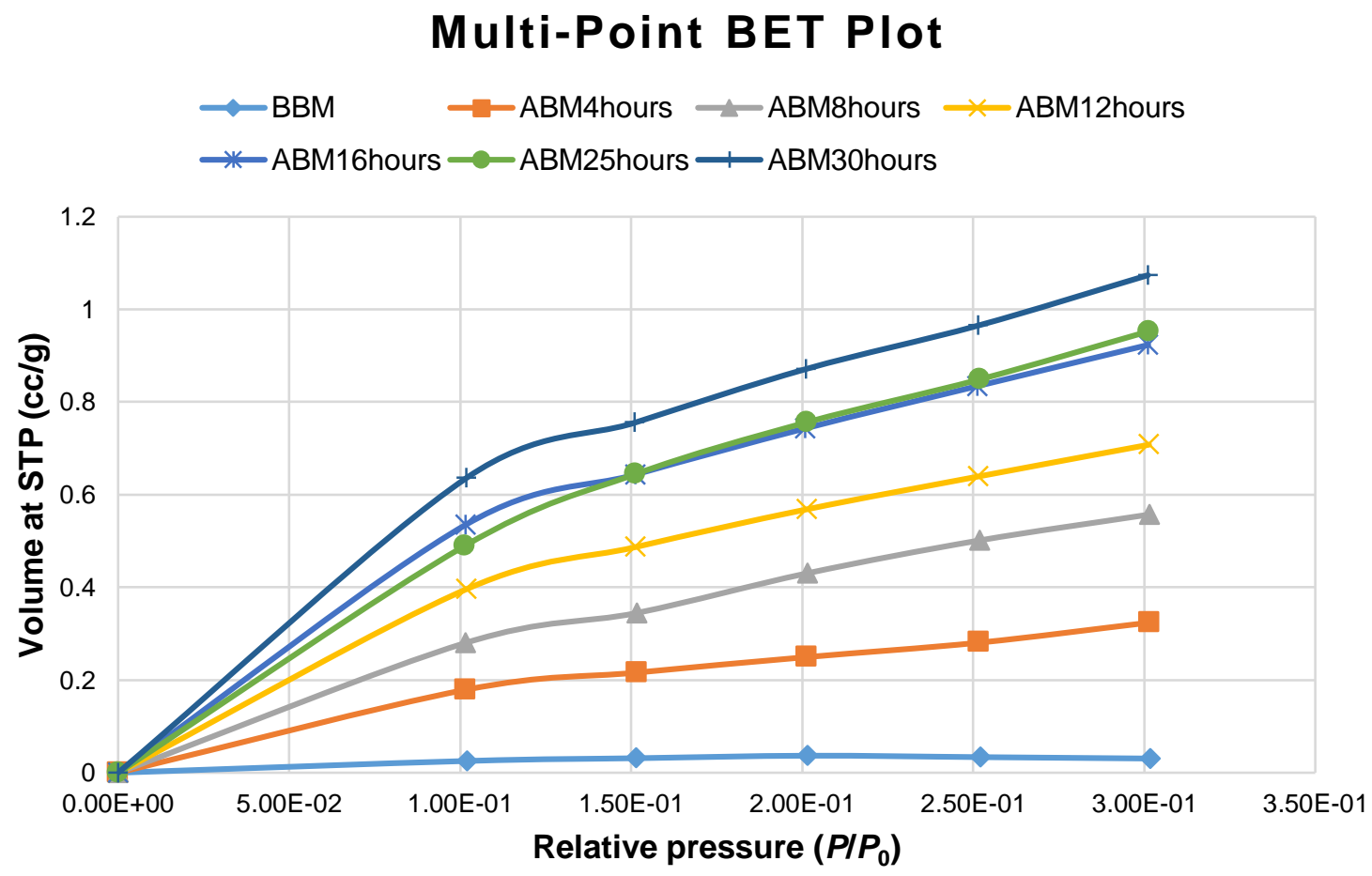

Fig. 5. Multi-point BET plot for all Jatropha seed biochar samples 


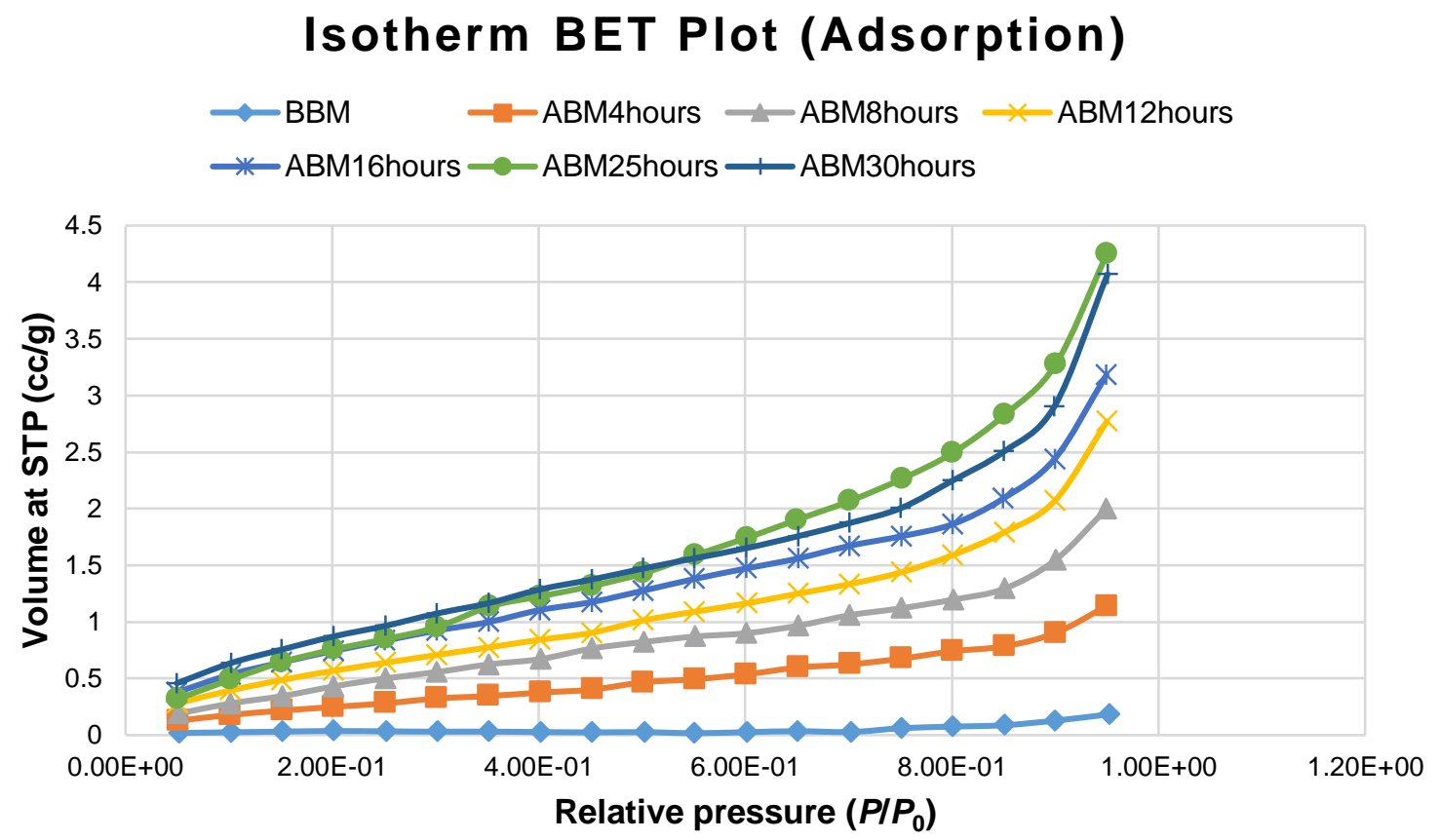

Fig. 6. Isotherm BET plot (adsorption) for all Jatropha seed biochar samples

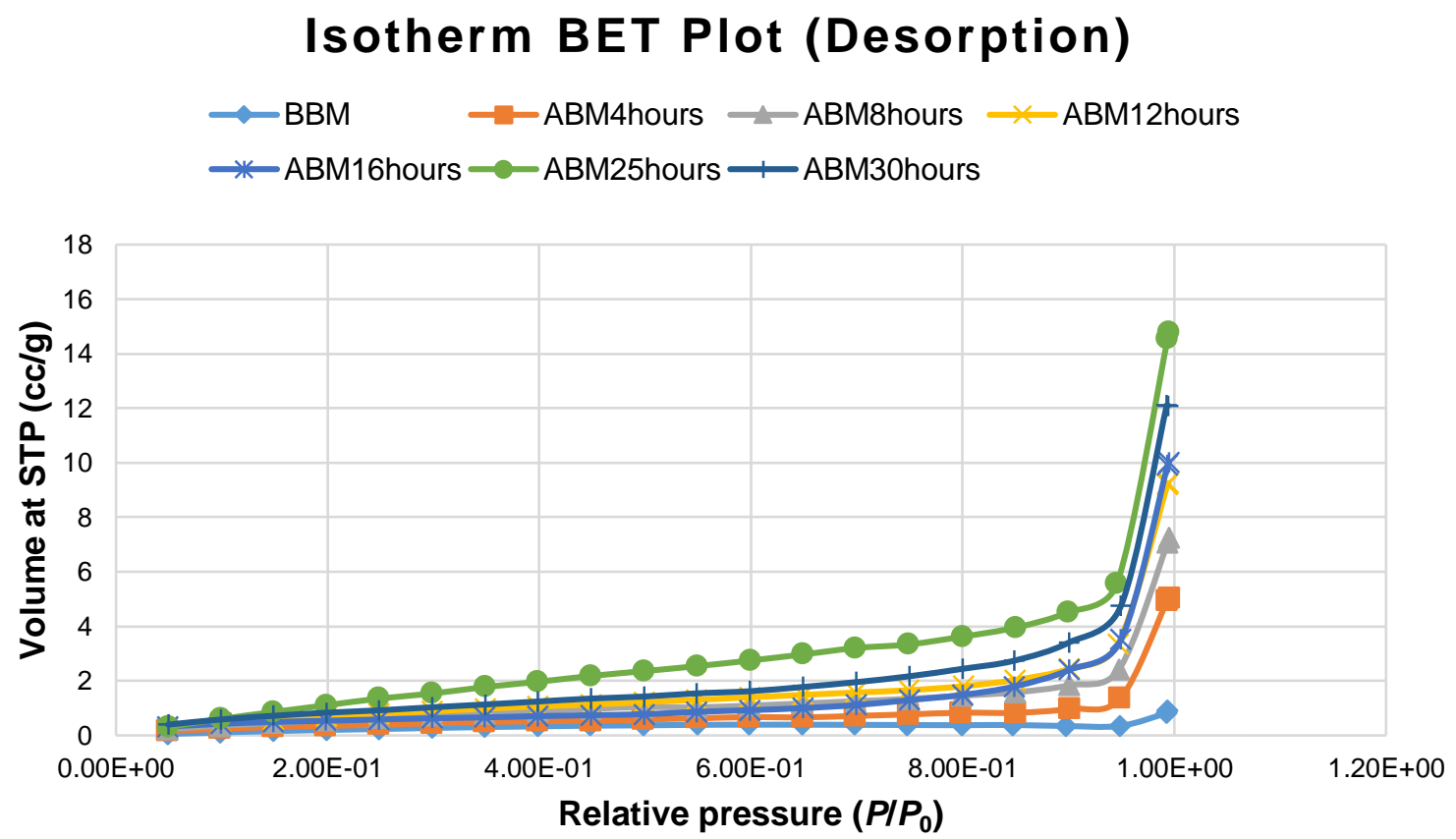

Fig. 7. Isotherm BET plot (desorption) for all Jatropha seed biochar samples 


\section{CONCLUSIONS}

1. After ball milling for $30 \mathrm{~h}$, SEM imagery indicated that the jatropha seed biochar samples were successfully reduced in size from 1 to $3 \mathrm{~mm}$ to the range $10 \mu \mathrm{m}$ to 600 $\mathrm{nm}$ within micro-nano range, hence a $90 \%$ reduction in size. The samples have not reached the grinding limit, even after 30 hours of ball milling.

2. EDS and BET analysis results respectively indicate an increased carbon mass percentage from 72.6 to $81.2 \%$ with surface area increased from 0.10 to $3.67 \mathrm{~m}^{2} / \mathrm{g}$ after 30 hours of ball milling.

3. FTIR shows increased transmittance after ball milling for 30 hours, reduction of the presence of moisture (alcohol, phenol, and water), with similar effects in surface functional groups peaks compared to chemical pretreated biochar by other literatures.

4. Resulting micro-nano carbon filler could be applicable as reinforcement filler in fabricating high strength composites due to the increased surface area, functional groups, and morphological structure. Characteristics and properties of the micro-nano carbon filler may modify mechanical, chemical, thermal, and electrical properties of the polymer matrix.

\section{FUTURE WORK}

Future recommendation includes; optimizing biochar yield with higher surface area by investigating various conditions of microwave pyrolysis, optimizing ball-ratio for ball milling processes may effectively achieve micro-nano size in less duration of time, and investigating the grinding limit of the microwave pyrolysis jatropha seed biochar.

\section{ACKNOWLEDGMENTS}

The authors are grateful for the support of Universiti Malaysia Sarawak (UNIMAS), Grant No. F02/CDRG/1826/2019.

\section{REFERENCES CITED}

Al-Wabel, M. I., Al-Omran, A., El-Naggar, A. H., Nadeem, M., and Usman, A. R. A. (2013). "Pyrolysis temperature induced changes in characteristics and chemical composition of biochar produced from conocarpus wastes," Bioresour. Technol. 131, 374-379. DOI: 10.1016/j.biortech.2012.12.165

ASTM D6556-14 (2014). "Standard test method for carbon black-Total and external surface area by nitrogen adsorption," ASTM International, West Conshohocken, PA, USA.

ASTM E1252-98 (2013). "Standard practice for general techniques for obtaining infrared spectra for qualitative analysis," ASTM International, West Conshohocken, PA, USA. 
ASTM E168-16 (2016). "Standard practices for general techniques of infrared quantitative analysis," ASTM International, West Conshohocken, PA, USA.

ASTM E2015-04 (2014). "Standard guide for preparation of plastics and polymeric specimens for microstructural examination. West Conshohocken, PA, USA.

ASTM E1508-12a (2019), "Standard Guide for Quantitative Analysis by EnergyDispersive Spectroscopy", ASTM International, West Conshohocken, PA, USA.

Audu, J., Irtwange, S.V., and Satimehin, A.A. (2018). "Thermal properties of jatropha seeds," Arid Zone J. of Eng., Tech., and Environ. 14(3), 437-449.

Bakly, S., Al-Juboori, R. A., and Bowtell, L. (2019). "Macadamia nutshell biochar for nitrate removal: Effect of biochar preparation and process parameters," J. Carb. Res. 5(3). DOI: $10.3390 / \mathrm{c} 5030047$

Budarin, V. L., Clark, J. H., Lanigan, B. A., Shuttleworth, P., Breeden, S. W., Wilson, A. J., Macquarrie, D. J., Milkowski, K., Jones, J., Bridgeman, T., et al. (2009). "The preparation of high-grade bio-oils through the controlled, low temperature microwave activation of wheat straw," Bioresource Technol. 100(23), 6064-6068. DOI:

10.1016/j.biortech.2009.06.068

Cheng, F., and Li, X. (2018). "Preparation and application of biochar-based catalysts for biofuel production," Catalysts 8(9). DOI: 10.3390/catal8090346

Eckert, J., and Börner, I. (1997). "Nanostructure formation and properties of ball-milled NiAl intermetallic compound," Mat. Sci. Eng. A-Struct. 239-240, 619-624. DOI: 10.1016/S0921-5093(97)00639-4

Figueiredo, M. K.-K., Romeiro, G. A., Silva, R. V. S., Pinto, P. A., Damasceno, R. N., d'Avila, L. A., and Franco, A. P. (2011). "Pyrolysis oil from the fruit and cake of Jatropha curcas produced using a low temperature conversion (LTC) process: Analysis of a pyrolysis oil-diesel blend," Energy Power Eng. 3(3), 332-338. DOI: 10.4236/epe.2011.33041

Garg, S., and Das, P. (2018). "High-grade activated carbon from pyrolytic biochar of Jatropha and karanja oil seed cakes - Indian biodiesel industry wastes," Biomass Convers. Biorefinery 8(3), 545-561. DOI: 10.1007/s13399-018-0308-8

Huang, Y.-F., Chiueh, P.-T., and Lo, S.-L. (2016). "A review on microwave pyrolysis of lignocellulosic biomass," Sustain. Environ. Res. 26(3), 103-109. DOI: 10.1016/j.serj.2016.04.012

Jouiad, M., Al-Nofeli, N., Khalifa, N., Benyettou, F., and Yousef, L. F. (2015). "Characteristics of slow pyrolysis biochars produced from rhodes grass and fronds of edible date palm," J. Analy. Appl. Pyroly. 111(1), 183-190. DOI: 10.1016/j.jaap.2014.10.024

Kadry, G. A. (2015). "Biodiesel production from Jatropha seeds," Am. J. Chem. Eng. 3(6), 89-98. DOI: 10.11648/j.ajche.20150306.13

Kanaujia, P. K., Naik, D. V., Tripathi, D., Singh, R., Poddar, M. K., Konathala, L. N. S. K., and Sharma, Y. K. (2016). "Pyrolysis of Jatropha curcas seed cake followed by optimization of liquid-liquid extraction procedure for the obtained bio-oil," J. Anal. Appl. Pyrol. 118, 202-224. DOI: 10.1016/j.jaap.2016.02.005

Kim, K. H., Kim, J.-Y., Cho, T.-S., and Choi, J. W. (2012). "Influence of pyrolysis temperature on physicochemical properties of biochar obtained from the fast pyrolysis of pitch pine (Pinus rigida)," Bioresource Technol. 118, 158-162. DOI: 10.1016/j.biortech.2012.04.094

Kloss, S., Zehetner, F., Dellantonio, A., Hamid, R., Ottner, F., Liedtke, V., Schwanninger, M., Gerzabek, M. H., and Soja, G. (2012). "Characterization of slow 
pyrolysis biochars: effects of feedstocks and pyrolysis temperature on biochar properties," J. Environ. Qual. 41(4), 990-1000. DOI: 10.2134/jeq2011.0070

Li, X., Li, K., Geng, C., El Mashad, H., Li, H., and Yin, W. (2019). "Biochar from microwave pyrolysis of Artemisia slengensis: Characterization and methylene blue adsorption capacity," Appl. Sci.-Basel 9(9). DOI: 10.3390/app9091813

Meri, N. H., Alias, A. B., Talib, N., Rashid, Z. A., Wan, W. A., and Karim Ghani, A. (2018). "Effect of chemical washing pre-treatment of empty fruit bunch (EFB) biochar on characterization of hydrogel biochar composite as bioadsorbent," IOP Conf. Ser.Mat. Sci. 358. DOI: 10.1088/1757-899X/358/1/012018

Odetoye, T. E., Abu Bakar, M. S., and Titiloye, J. O. (2019). "Pyrolysis and characterization of Jatropha curcas shell and seed coat," Niger. J. Technol. Dev. 16(2), 71-77. DOI: 10.4314/njtd.v16i2.4

Srivastava, S., Singh, V. P., Gupta, G. N., and Sinha, A. (2013). "Change in seed index of fresh and infested Jatropha seeds," Int. J. Life Sci. 1(2), 89-92.

Supriyono, Ngafwan, and Joharwan, J. W. (2018). "The effect of the ball size on the product characteristics of shaker HEM to produce nano particle from bamboo charcoal," IOP Conf. Ser.-Mat. Sci. 403. DOI: 10.1088/1757-899X/403/1/012090

Tongpoothorn, W., Sriuttha, M., Homchan, P., Chanthai, S., and Ruangviriyachai, C. (2011). "Preparation of activated carbon derived from Jatropha curcas fruit shell by simple thermo-chemical activation and characterization of their physico-chemical properties," Chem. Eng. Res. Des. 89(3), 335-340. DOI: 10.1016/j.cherd.2010.06.012

Tsai, W.-T., Huang, P.-C., and Lin, Y.-Q. (2019). "Characterization of biochars produced from dairy manure at high pyrolysis temperatures," Agronomy 9(10). DOI: 10.3390/agronomy9100634

Ugbogu, A. E., Akubugwo, E. I., Uhegbu F. O., Chinyere, C. G., Ugbogu, O. C., and Oduse, K. A. (2014). "Quality assessment profile of Jatropha curcas (L) seed oil from Nigeria," Int. Food Res. J. 21(2), 735-741.

Umemoto, M., Liu, Z. G., Masuyama, K., Hao, X. J., and Tsuchiya, K. (2001). "Nanostructured Fe-C alloys produced by ball milling," Scripta Mater. 44(8-9), 17411745. DOI: 10.1016/S1359-6462(01)00794-1

Wang, B., Gao, B., and Wan, Y. (2019). "Comparative study of calcium alginate, ballmilled biochar, and their composites on aqueous methylene blue adsorption," Environ. Sci. Pollut. R. 26(12), 11535-11541. DOI: 10.1007/s11356-018-1497-1

Wu, Q., Xian, Y., He, Z., Zhang, Q., Wu, J., Yang, G., Zhang, X., Qi, H., Ma, J., Xiao, Y., and Long, L. (2019). "Adsorption characteristics of Pb (II) using biochar derived from spent mushroom substrate," Sci. Rep. 9, 15999 DOI: 10.1038/s41598-01952554-2

Zhang, Q., Wang, J., Lyu, H., Zhao, Q., Jiang, L., and Liu, L. (2019). "Ball-milled biochar for galaxolide removal: Sorption performance and governing mechanisms," Sci. Total Environ. 659, 1537-1545. DOI: 10.1016/j.scitotenv.2019.01.005

Zhang, S., Dong, Q., Zhang, L., and Xiong, Y. (2015b). "High quality syngas production from microwave pyrolysis of rice husk with char-supported metallic catalysts," Bioresour. Technol. 191, 17-23. DOI: 10.1016/j.biortech.2015.04.114

Zhang, Z., Macquarrie, D. J., De bruyn, M., Budarin, V. L., Hunt, A. J., Gronnow, M. J., Fan, J., Shuttleworth, P. S., Clark, J. H., and Matharu, A. S. (2015a). "Lowtemperature microwave-assisted pyrolysis of waste office paper and the application of bio-oil as an Al adhesive," Green Chem. 17(1), 260-270. DOI:

10.1039/C4GC00768A 
Zhou, R., Lei, H., and Julson, J. (2013). "The effects of pyrolytic conditions on microwave pyrolysis of prairie cordgrass and kinetics," J. Anal. Appl. Pyrol. 101, 172-176. DOI: 10.1016/j.jaap.2013.01.013

Zuo, W., Shi, B., Chen, S., Zhou, X., Duan, Y., and Liao, A. (2018). "Low-cost and efficient adsorbent derived from pyrolysis of Jatropha curcas seeds for the removal of $\mathrm{Cu}^{2+}$ from aqueous solutions," Chem. Ecol. 34(7), 655-674. DOI:

$10.1080 / 02757540.2018 .1472246$

Article submitted: December 9, 2019; Peer review completed: February 29, 2020;

Revised version received: March 10, 2020; Accepted: March 11, 2020; Published: March 20, 2020.

DOI: $10.15376 /$ biores. 15.2.3237-3251 